\title{
Considerations for tailings facility design and operation using filtered tailings
}

\author{
B. Ulrich Knight Piésold and Co., USA \\ J. Coffin Knight Piésold and Co., USA
}

\begin{abstract}
The use of filtering technology has improved considerably during the past few years, and tailings disposal facilities using filtered tailings are becoming more and more commonplace. Where once this method was only deemed suitable for relatively small-scale operations, technological advances are now being realised for large-scale operators. Often this application appears to be, and in fact is, relatively simple and straightforward. As with other tailings preparation methods, the use of filtered tailings provides no inherent panacea for tailings placement. Designers are advised to adopt designs thoughtfully, using site-specific data, information and tailings properties to ensure the method is employed rationally and that the resulting facility designs are flexible enough to accommodate changes to presumed operational design criteria. Practical experiences with facilities where less than optimal performance was achieved are presented.
\end{abstract}

\section{Introduction}

The use of the filtering process in tailings management has been growing fairly rapidly over the past several years; however, there are a disproportionately low number of publications regarding this topic. Davies et al. (2010) indicates that there are approximately triple the number of filtered tailings facilities as there are surface paste tailings facilities, but the number of publications for surface paste facilities far outweigh the number of publications for filtered tailings facilities. This disparity is primarily due to the perceived relative ease of the design and operation of a filtered tailings facility compared to a surface paste facility, but also the uniqueness, complexity and idiosyncrasy of surface paste facilities. In fact, the industry bible on the topic, 'Paste and Thickened Tailings - A Guide' (Jewell and Fourie, 2006) discusses the topic of surface filtered tailings facilities only in passing, although there is a good discussion on the filtering process itself.

Filtered tailings facilities may be perceived as being very ordinary and somewhat undeserving of extensive coverage in the literature. This perception is somewhat true as there are many ordinary filtered tailings facilities; however as the technologies continue to develop in the processing of filter plants, very significant facilities are now being designed that will bring this application to ever greater heights. In fact, USFS (2010) reports on an operation that will be producing filtered tailings at the rate of 68,000 tonnes per day with a facility that will ultimately store 311 million tonnes of tailings to a height of 150 metres (USFS, 2010).

In the tailings thickening continuum, filtered tailings are typically seen to be at the opposite end of the spectrum from conventional slurry tailings. Description of the tailings thickening continuum can be found elsewhere (e.g. Jewell, 2006; Davies and Rice, 2001). Filtered tailings, i.e. 'dewatered' tailings, cannot be transported by pipeline due to their low moisture content and therefore filtered tailings are normally transported by conveyor or truck, deposited, spread and compacted to form the desired deposit. As discussed by Ulrich (2003), there are no universal remedies for tailings storage and every tailings facility should be designed based on site-specific requirements. The designer should realise the wide variety of applications available for tailings storage; filtered tailings technology is not a panacea for tailings management, but rather a possible option for the tailings designer under certain circumstances (Davies and Rice, 2001). 


\section{Terminology}

Filtered tailings facilities are often referred to as 'dry stacks' (e.g. Davies and Rice, 2001; USFS, 2010; Davies et al., 2010; Lupo and Hall, 2010), while contradictory terms are also used for certain portions or aspects of the deposit such as 'wet cake' (Davies and Rice, 2001; Davies et al., 2010; Newman et al., 2010), and zones of the dry stack that may be 'overly wet' (Lupo and Hall, 2010). Davies and Rice (2001) indicate that the term dry stack has been adopted by designers and regulatory authorities for filtered tailings facilities, admitting that the facilities are not truly dry, but that as long as practitioners bear in mind that this is a somewhat misused term, it is acceptable to continue using this terminology.

The term dry stack, is rather misleading and generally not a good engineering term since the target moisture content coming from the filter plant is typically desired to be somewhere around the optimum moisture content based on the Proctor compaction procedure (either the standard or modified test, as determined by the design engineer). Geotechnical engineers associate the optimum moisture content with moisture levels just below full saturation after compaction, thus terming such a facility as a dry stack is a misnomer.

The present author would encourage practitioners to abandon the use of the term 'dry stack' in favour of the more straightforward term, 'filtered tailings'. It is not desirable to unintentionally mislead the general public at large with an industry term that is noticeably misused.

\section{The basics}

Rosemont Copper Company (2008) provided information suggesting that experience shows the most applicable projects for considering the use of filtered tailings are those that have one or more of the following attributes:

- The project is located in an arid region where water conservation is crucial.

- The project is located in a cold region where water handling is very difficult in winter.

- The project is located in an area where seismicity prohibits some forms of conventional tailings impoundments.

- Topographic considerations exclude conventional dam construction.

- Storage efficiencies of embankment dams are not economical.

- The flow sheets show economic recovery is enhanced by tailings filtration.

- The operating and/or closure liability of a conventional tailings impoundment exceed the incremental increase to develop a filtered tailings facility.

The concept of a filtered tailings facility, its design and operation is fairly straightforward. The tailings are first thickened to a given state, generally using conventional thickeners. The thickened tailings are then delivered to the filter plant. There is a large variety of filters that may be used, including vacuum types (drum, disc, and belt) and pressure types (plate and frame, and belt press). Bedell (2006) provides a great deal of information regarding thickening and filtering of tailings. The filtered product is often referred to as 'filter cake'.

As with other mine waste facilities, filtered tailings facilities may be free-standing, side hill or cross-valley structures, and may be constructed in conjunction with other facilities, such as waste rock facilities. If the filtered tailings have a high moisture content and/or are moderately plastic, it may be necessary to construct a significant engineered embankment to impound the filtered tailings.

Once the tailings are produced in a filter cake they must be transported to the containment facility. This is usually accomplished using trucks or conveyors. Once at the tailings facility, the filtered tailings are typically mechanically spread and compacted as needed in order to achieve the desired engineering behaviour. As the tailings are spread into place, additional moisture may be driven away from the tailings (if climatic 
conditions are favourable, and moisture may be reintroduced into the tailings in adverse climatic conditions). A good degree of compaction can be beneficial to the overall slope stability of the facility, as increased frictional behaviour can be realised, possibly also achieving an unsaturated state where negative pore pressure may develop and further increase the overall stability of the facility against slope instability.

In locations where precipitation occurs seasonally, it is often beneficial to have separate areas within the tailings facility to contain rainy season tailings and dry season tailings. The dry season tailings are often placed in the outermost extents of the facility, where they can be compacted to a degree where they can provide containment for the rainy season tailings (which may receive little to no compaction and placed remotely from the outermost compacted tailings which provide their confinement). It is obviously important that the designer of the facility considers how much of each material is placed over time so that the outer structural zone is constructed in time to provide containment of the rainy season tailings. This staged design development is similar to ore loading plans that are developed for heap leach facilities.

Facilities may be constructed with rocky covers on their outer slopes for protection against erosion. Some facilities must be designed with a significant toe buttress to improve slope stability conditions. An example cross section diagram of a typical filtered tailings facility is provided on Figure 1.

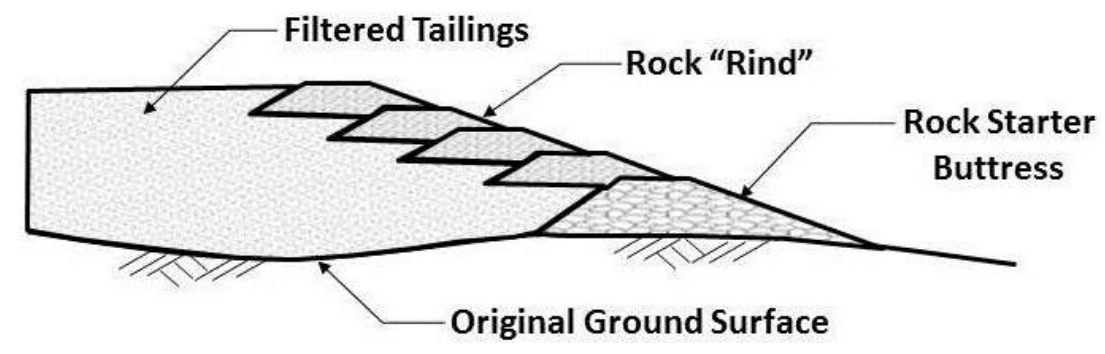

\section{Figure 1 Cross section through typical filtered tailings facility showing rock starter buttress and rock 'rind'}

Many approaches may be taken to improve the stability of a facility, for example, many filtered tailings facilities are constructed with at least a limited amount of drains at their base to intercept and convey free water that may accumulated within the deposit. It is important that engineers designing these facilities understand how much water may accumulate in the tailings mass, whether or not a phreatic surface may develop, and to what extent a pore pressure regime may develop. Such pore fluids may include water from external sources (groundwater inflow or infiltration from precipitation events) and/or an increase in the degree of saturation due to self-weight consolidation. An example of pore pressure monitoring in a filtered tailings facility is provided on Figure 2 . 


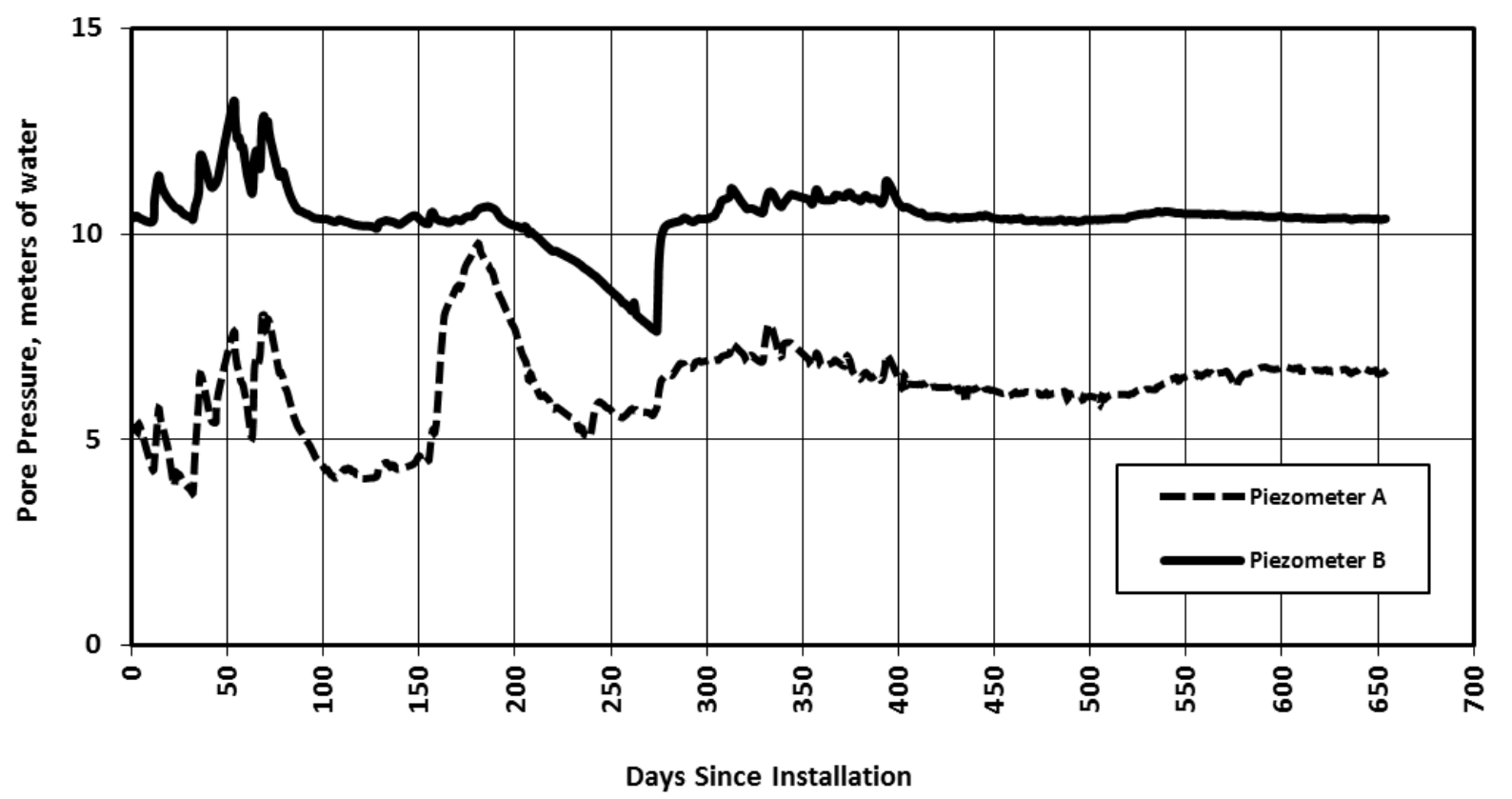

\section{Figure 2 Example of pore pressure readings over time from drive-point vibrating wire piezometers installed in a filtered tailings facility}

Figure 2 provides a summary of data from two drive-point type vibrating wires installed in a filtered tailings facility. The two instruments were installed in relatively close proximity to each other (approximately $10 \mathrm{~m}$ ), though at slightly different depths, and were installed fairly early in the facility's operation when it was recognised that the moisture content of the filter cake was above the design assumption. The pore pressure condition and response to loading has been closely monitored, and coupled with in situ and laboratory testing and geotechnical analyses in order to develop guidance on the construction, loading, and development of the facility. Additional information may be published in the future as it makes a very good case history on performance monitoring and the use of geotechnical analyses. Nevertheless, the figure illustrates the fact that pore pressure can develop in filtered tailings masses, and designers are reminded to be aware of conditions that may warrant similar monitoring.

\section{$4 \quad$ Filters 101}

There are two general categories of filters currently in use: pressure filters and vacuum filters. Within those two basic categories, there is a further subdivision. Drum, disc, and belt filters form the broad sub-families of vacuum filters, while plate and frame and belt presses form the broad sub-families of pressure filters.

Filters within the vacuum filter categories generally work in similar fashions. That is, there is generally a mechanism that rolls or turns, and a portion of that belt, drum or disc is submerged in slurry. As the mechanism turns, slurry clings to the filter. A vacuum acting from the opposite side draws moisture from the slurry. As the rotating mechanism completes its rotation the dewatered slurry is allowed to fall from the filter (possibly with assistance of compressed air or a mechanical scraper). An optional washing step can be added to remove additional chemicals, such as dissolved solids (Bedell, 2006).

Pressure filters do not share many characteristics with vacuum filters. Plate and frame filter presses are dewatering apparatuses that utilise pressure to remove the liquid from slurry. In a plate and frame filter the feed enters the press and fills the void area between two plates using a pump suitable for pumping at moderate pressures. The liquid is forced through the filter media which is affixed to each side of the plates. The solids remain in the void between the plates until the plates discharge the filtered solids. Large plate and frame filter presses have mechanisms to move the plates, allowing discharge of the solids from the chambers. Solids discharged from the filter press typically fall into a hopper or directly onto a conveyor belt for delivery to the next stage of the operation (Kubach, 2010). 
A pressure belt filter dewaters by applying pressure to slurry to squeeze out fluid. Slurry sandwiched between two tensioned porous belts pass between rollers of various diameters. Increased pressure is created as the belt passes between the rollers. Many variations of belt filtration processes exist, but all tend to incorporate the following basic features: a gravity drainage zone, low pressure squeezing zones, and high pressure squeezing zones. Advanced designs provide a large filtration area, additional rollers, and variable belt speeds that can further reduce moisture content of the filter cake (US EPA, 2000).

Bedell (2006) reported that pressure filters were not then generally used for high volume applications. Even though only a few years have passed since that observation was made, thickener technology has now progressed to a point where plate and frame pressure filters are leading the way to high output production of filtered tailings.

\section{$5 \quad$ Material properties}

Various authors have commented on the importance of understanding material properties of filtered tailings in advance of the design process, and also on the necessity of obtaining and testing samples during the operational life of a facility, and therefore there will be very little discussion on that topic presented here. Little has been published regarding in situ testing of filtered tailings themselves, and in many cases such activities would be only of minimal benefit. However, when filtered tailings facilities begin to approach heights exceeding 100 metres, it seems warranted to conduct in situ testing especially as a way to check on the accuracies of laboratory testing and analytical predictions, for example if particle breakdown is foreseen (since particle breakdown may result in decreased permeability and a possible development of a phreatic surface).

As discussed by Davies and Rice (2001) the parameters that need to be understood include:

- shear strength and shearing behaviour

- moisture retention

- hydraulic conductivity characteristics

- moisture-density relationship.

Davies and Rice (2001) continued that the moisture-density relationship indicates in situ density expectations for compacted materials, and that there is often a sensitivity of that degree of compaction for a given moisture content, recognising that the optimal degree of saturation is usually between 60 and $80 \%$.

The present author would like to add to this list of important soil parameters - the Atterberg limits. With the ever-improving technology of filter plants, clayier tailings are now being produced more and more often using filtering technologies. Designers should consider and indeed anticipate changes in orebodies and assess seemingly subtle changes in Atterberg limits and the associated impacts of those changes on the material shear strength, shearing behaviour (i.e. contractive versus dilatant or ductile versus brittle behaviour), and permeability.

At one mine site the author has worked at, the tailings were identified as being low to non-plastic based on geological considerations. However, once in production, the tailings were found to have a greater amount of clay, and the design target moisture content fell between the liquid limit and the plastic limit; thus, the tailings at that moisture content act as a plastic, rather than as a granular material. To compound the problem, the filters could not remove as much moisture as designed due to the higher fines and clay content. This combination of higher moisture content and higher plasticity is far from optimum and the deposited filtered tailings behaved adversely to the design intent, requiring a significant amount of engineering analyses, instrumentation and in situ testing.

This is a convenient place to discuss moisture content. There are two forms of the gravimetric water content equation. Metallurgists often use the formula:

$$
\mathrm{w}_{\mathrm{M}}=\mathrm{m}_{\mathrm{W}} / \mathrm{m}_{\mathrm{T}}
$$


Where:
$\mathrm{W}_{\mathrm{M}}=$ the moisture content as defined by metallurgists.
$\mathrm{m}_{\mathrm{W}}=$ the mass of water.
$\mathrm{m}_{\mathrm{T}} \quad=$ the total mass of solids plus water.

Geotechnical engineers, on the other hand, most commonly use the following equation:

$$
\mathrm{w}_{\mathrm{G}}=\mathrm{m}_{\mathrm{W}} / \mathrm{m}_{\mathrm{S}}
$$

Where:

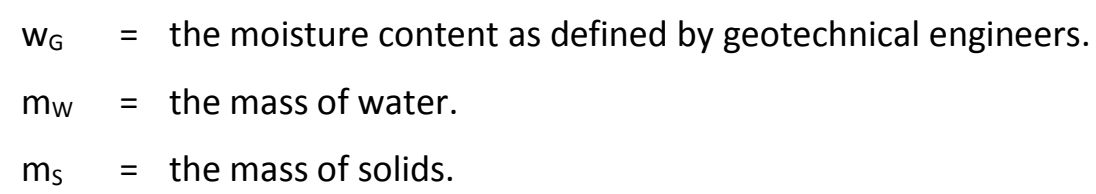

The difference in these formulas can lead to considerable confusion unless this difference is understood by the process plant designer and the geotechnical engineer and the difference is considered in the design. The difference in these two moisture contents may be minor, but if working with a material that may exhibit a plastic behaviour, the difference can be very meaningful.

To adjust one form of moisture content to the other:

$$
w_{G} / w_{M}=m_{T} / m_{S}
$$

or

$$
w_{G} / w_{M}=\left(m_{W}+m_{s}\right) / m_{S}
$$

or, if you are provided with one form of moisture content and you require the other:

$$
w_{G}=w_{M} /\left(100-w_{M}\right)
$$

or

$$
\mathrm{W}_{\mathrm{M}}=\mathrm{w}_{\mathrm{G}} /\left(100+\mathrm{W}_{\mathrm{G}}\right)
$$

Davies and Rice (2001) report on the trafficability of newly placed filtered tailings, providing the following observations:

- Filtered tailings are generally produced at or slightly above their optimum moisture content and as such trafficability problems can arise especially in wet environments. The tailings surface can quickly become un-trafficable resulting in significant placement problems. Facility designers must take this matter into account to ensure the operation is not unduly hampered during the wet season.

- The degree of compaction required to achieve trafficability can be higher than the compaction required to achieve slope stability goals. This can work favourably for geotechnical requirements.

- In some designs there is a requirement to compact the tailings to a higher density in at least the outer reaches of the facility. This requirement increases the need for construction quality control.

For facilities designed to accommodate materials that are produced during seasonally unfavourable periods, such as rainy seasons and/or cold seasons (usually this requires storage in a portion of the facility that is remote from the outer slopes of the facility) these trafficability issues during unfavourable weather may be greatly reduced or eliminated altogether.

\section{Trends and operations}

Davies and Rice (2001) reported more than 10 years ago that the upper limit to filtered tailings plant production appeared to be 14,000 tonnes per day. Currently, there are facilities designed to produce 
product at nearly five times that amount. Trends in the industry are now for larger-scale mining operations to consider the use of tailings filtering technologies for the surface disposal of tailings. Major advances in filtering technology are helping to lead the way to ever-increasing use of this application.

Rosemont Copper Company, who proposes to produce tailings at a rate of 76,200 tonnes per day, provides a summary of operating mines using surface filtered tailings as part of their tailings management plan. The following table has been modified after Rosemont Copper Company (2008).

\section{Table 1 Summary of significant operating filtered tailings operations}

\begin{tabular}{lllc}
\hline Mine & Location & Ore type & Production tpd \\
\hline Alcoa & Australia & Alumina & 35,500 \\
Chingola & Zambia & Copper & 24,000 \\
La Coipa & Chile & Gold and silver & 16,000 \\
Mantos de Oro & Chile & Gold and silver & 15,000 \\
Vaal Reef & South Africa & Gold and uranium & 10,000 \\
Randfontein Estates & South Africa & Gold and uranium & 10,000 \\
Lihir Island & Papua New Guinea & Gold & 7,500 (est.) \\
El Sauzal & Chihuahua, Mexico & Silver and gold & 5,300 \\
Gecamines & Zaire & Copper & 5,000 \\
Nabalco & Australia & Alumina & 5,000 \\
Mantos Blanco & Chile & Copper & 4,000 \\
Alamo Dorado & Sonora, Mexico & Silver and gold & 3,500 \\
Pogo & Alaska, USA & Gold & 2,500 \\
Raglan & Quebec, Canada & Lead/zinc & 2,000 \\
Greens Creek & Alaska, USA & Gold, silver and zinc & 1,500 \\
Eskay Creek & BC, Canada & Copper & 300 \\
Nixon Fork & Alaska, USA & Gold & 150 \\
\hline & & &
\end{tabular}

\section{$7 \quad$ Experiences}

Technology for preparing filtered tailings is currently considerably more expensive per tonne of tailings stored than for conventional slurry systems. Filtered tailings facilities often have regulatory attraction, and smaller footprints can be accomplished with this type of facility (Davies and Rice, 2001). A significant benefit of filtered tailings is the probable ease of reclamation of the facility, compared to a conventional, thickened or paste tailings facility. The possibility of placing a closure cover immediately upon cessation of operations can be a very attractive option in a closure plan.

The author has gained experience with a variety of different applications for filtered tailings during the past few years, including designs and installations. Three of those applications are worthy of a brief discussion here.

One project completed for a confidential client was the design of a filtered tailings facility in Latin America that would be built upon an existing, though inactive, tailings facility. The current inactive facility is a typical spigotted side-hill style 'sand dam' where tailings had been spigotted onto a beach, and the outer 'wall' was raised by excavating portions of the sandy beach material for use in constructing a small berm adjacent to 
and upstream of the wall, upon which the slurry deposition line was placed. By continuing this operation slowly and allowing the beach to adequately desiccate, a stable structure can be developed. When design work commenced on this project the facility had been inactive for several years, and the upper surface had become quite firm. This condition gave the owner a false sense of comfort as the underlying silty portions of the impounded tailings upstream of the sandy beach mass still exhibited a phreatic surface and was still in a contractive state.

The owner modified a planned site investigation which had included cone penetration tests (CPTs). The modified site investigation included only standard penetration tests (SPTs) together with sampling and laboratory testing. The use of the CPT (an electronic instrument equipped with strain gauges and a transducer to measure and record resistance to penetration at its tip and sleeve as the probe is pushed through a soil deposit as well as pore-pressure both during penetration and during pauses in the penetration process) is widespread in assessing materials such as those present in a tailings facility.

Basic correlations can be used to assess the general material type (i.e. sand, silt or clay), layering and the pore pressure regime within the soil mass. On the other hand, the SPT is a simple (non-instrumented) split barrel sampler which is driven into a soil deposit by a $63.5 \mathrm{~kg}$ hammer falling $0.76 \mathrm{~m}$, and the number of blows required to drive the sampler each $0.15 \mathrm{~m}$ increment is recorded; the blows required to drive the sampler the final $0.3 \mathrm{~m}$ is recorded as the measured SPT ' $\mathrm{N}$ ' value. With the SPT device a sample is recovered but very little information can be gained regarding the pore pressures that exist in the soil mass. As the SPT approach was taken rather than using the CPT, little information was gained regarding the in situ pore pressure regime within the facility. The owner agreed to allow piezocone testing during upcoming design stages. The selection of filtered tailings for this project was made based on the following design considerations:

- The limited amount of space available for tailings storage made the higher density achieved by filtered tailings very desirable.

- In order to reduce the potential for a rapid loading condition in the underlying tailings slimes, filtered tailings was the selected option to help reduce the increased stresses imposed on the slimes.

- For environmental reasons, it was decided that the future facility would have to be constructed upon a geosynthetic liner which would be overlain by an underdrain system. The selection of filtered tailings greatly simplified the design.

- The area is environmentally sensitive with migratory fauna that required protection from the presence of process water ponds.

The second facility design was carried out for Nevada Copper's Pumpkin Hollow project to store combined waste and tailings in a single facility in the western US. The filtered tailings option was selected by the owner as a preferred approach in consideration of limited available water leases for use in their mining operation. The operation would combine filtered tailings produced at the rate of up to 54,000 tonnes per day, possibly together with waste rock, both of which are chemically benign. The author's involvement in this project was limited to the early planning stages, and thus additional design details are not available for this paper. What is notable for this project is the magnitude of materials that would be involved in the operation.

The third facility carried out for a confidential client is located in Latin America and is an operating facility. Several practical lessons have been learned since the facility came into operation. The facility is situated in a v-shaped valley and the design includes separate areas for placement of material during rainy season and dry season. The pre-deposition construction work included the construction of a series of underdrains, a starter berm and a seepage/sedimentation pond. As the facility gains height, a rocky rind is placed on the outer slope. The rock shell serves to provide erosion protection from precipitation, and also provides a drain into which any water seeping from the deposit may be safely conveyed to the sedimentation pond which is situated at the foot of the facility. 
As with many similar facilities, the operation includes delivery of the filtered tailings by conveyor to a central point. From the conveyor the material is pushed into place by a dozer before being compacted by subsequent dozing activities. These activities would tend to drive off additional moisture, especially in the furthest reaches from the conveyor, in this case near the outer containment structure.

Start-up of the facility commenced during unseasonal precipitation events, and, since the facility is situated in a north-south oriented v-shaped valley, the facility is exposed to sunshine for only a limited amount of time each day when there is no precipitation. In addition, the filter plant was not functioning optimally at start-up, and the filter cake produced was higher than the design value. This combination of factors hampered the early development of the facility to a point where some alternative arrangements were needed to get the operation to function adequately. Remedial measures at that site are still underway.

\section{Environmental prizes}

As previously discussed, there are several environmental benefits associated with the use of filtered tailings, including a reduced footprint, reduced water consumption, and improved closure opportunities. The improved closure opportunities include the ability to begin the closure work essentially at the cessation of operations (and concurrently on side slopes).

Ward Wilson and his colleagues have written extensively (see for example Wilson et al., 2006) on the environmental merits of homogeneously blended tailings and waste rock where the amount of tailings used just precisely fills the voids between the rock particles. This mixture is said to have the (static) shear strength characteristics of waste rock and the permeability characteristics of tailings. Thus it may be possible to create facilities that are at least somewhat steeply sloping (note that precaution must be used in seismic areas as the material may be prone to liquefaction in some cases) and there may be benefits in warding off the occurrence of acid rock drainage (ARD). The benefit in ARD reduction lies in the concept of the reduction on oxygen diffusion rates. As discussed by Wilson et al. (2006), it is well documented that a significant reduction in oxygen diffusion rates occurs when saturation values exceed $85 \%$. There is a good opportunity for designers to also assess this possible benefit in filtered tailings facilities. It may be advantageous to investigate whether this level of saturation can be achieved through specified compaction efforts, and to also assess whether this moisture will remain in the tailings over the long term (i.e. by assessing the drain-down moisture content and field capacity moisture content of the filtered tailings).

\section{$9 \quad$ Conclusions}

Filtered tailings facilities are becoming more and more common as technological advances make this application increasingly feasible as a viable tailings storage option. As with other such disposal options, the decision to select filtered tailings should be made on site-specific requirements and considerations, including capital, operating and closure costs, but also based on other matters such as the outcome of a risk assessment, water usage and availability and environmental matters.

\section{References}

Bedell, D. (2006) Thickening and filtration, in Paste and Thickened Tailings - A Guide, 2nd edition, R.J. Jewell and A.B. Fourie (eds), Australian Centre for Geomechanics, Perth, Australia, pp. 95-123.

Davies, M.P., Lupo, J., Martin, T., McRoberts, E., Musse, M. and Ritchie, D. (2010) Dewatered tailings practice - trends and observations, in Proceedings Fourteenth International Conference on Tailings and Mine Waste, Vail, Colorado, USA, A.A. Balkema, The Netherlands, pp. 133-142.

Davies, M.P. and Rice, S. (2001) An alternative to conventional tailing management - "dry stack" filtered tailings, in Proceedings Eighth International Conference on Tailings and Mine Waste, Fort Collins, Colorado, USA, A.A. Balkema, The Netherlands, pp. 411-422.

Jewell, R.J. (2006) Introduction, in Paste and Thickened Tailings - A Guide, 2nd edition, R.J. Jewell and A.B. Fourie (eds), Australian Centre for Geomechanics, Perth, Australia, pp. 3-9.

Jewell, R.J. and Fourie, A.B. (eds) (2006) Paste and Thickened Tailings - A Guide, 2nd edition, Australian Centre for Geomechanics, Perth, $242 \mathrm{p}$.

Kubach, C. (2010) Dewatering equipment, removing solids from liquid-solid mixtures (slurries), viewed 7 November 2010, http://www.mine-engineer.com/mining/plate.htm. 
Lupo, J. and Hall, J. (2010) Dry stack tailings - design considerations, in Proceedings Fourteenth International Conference on Tailings and Mine Waste, Vail, Colorado, USA, A.A. Balkema, The Netherlands, pp. 327-334.

Rosemont Copper Company (2008) Filtered tailings dry stacks current state of practice final report, prepared by AMEC Earth \& Environmental, Inc., viewed 21 November 2012, http://rosemontcopper.com/assets/docs/reports_10-8-10/tailings_white_ paper/tailings_dry_stacks-_white_paper-final.pdf.

Ulrich, B. (2003) Toward a sensible use of paste tailings, Mining Environmental Magazine, The Mining Journal Limited, May, London, pp. 21-23.

US EPA (2000) United States Environmental Protection Agency. Biosolids technology fact sheet, Belt Filter Press, EPA 832-F-00-057, September, pp. 1-7.

USFS (2010) EIS Environmental impact statement Rosemont Copper Project, viewed 30 October 2010, http://www.rosemonteis.us/. Wilson, G.W., Miskolczi, J., Dagenais, A., Levesque, I., Smith, Q., Lanteigne, L., Hulett, L. and Landriault, D. (2006) The application of blended waste rock and tailings for cover systems in mine waste management, in Proceedings 7th International Conference on Acid Rock Drainage (ICARD), 26-30 March, viewed 30 November 2012, http://www.imwa.info/docs/imwa_2006/2424Wilson-BC.pdf. 